\title{
TEMPO-RHYTHMIC ABILITIES OF THE GYMNASTS AS A FACTOR DETERMINING THE DIFFICULTY OF COMPOSITE SOLUTION OF COMPETITIVE ROUTINE IN GROUP ROUTINES DEPENDING ON THE CHOICE OF MUSICAL ACCOMPANIMENT
}

\author{
Aleksandra Suprun ${ }^{1}$, Elena Medvedeva ${ }^{1}$, Anna Titova ${ }^{2}$, Vera Borisova ${ }^{2}$ \\ ${ }^{1}$ Lesgaft National State University of Physical Education, Sport and Health, \\ Saint-Petersburg (Lesgaft NSU, Saint-Petersburg), Russia \\ ${ }^{2}$ Tula State Lev Tolstoy Pedagogical University, Tula, Russia
}

\begin{abstract}
Starting from 2018 the judges began to evaluate the level of difficulty of the compositions with an open scale according to the rules of the competition. The article is devoted to the evaluation of the compositional difficulty of competitive compositions of group routines in rhythmic gymnastics. One of the factors that determines both the difficulty of the composition and the synchronization of motor interaction execution by sportswomen in group routines is defined. The purpose of this research is to justify the necessity of taking into account tempo-rhythmic abilities of gymnasts that predetermine difficulty of compositional decision of competitive program in group routines. The objective of this study is to reveal the correlational interconnections between tempo-rhythmic abilities and expert evaluations of synchronicity of group motor activity. The methods that were applied in are an expert evaluation that assesses the synchronization of motor actions of gymnasts in group routines and testing that consists of listening to and playing of parts of pieces of music of different rhythmic patterns. The revealed correlational interconnections allow increasing the synchronicity of motor actions of gymnasts in group routines that will make competitive programs more qualitative and spectacular.
\end{abstract}

Key words: rhythmic gymnastics, group routines, synchronization of motor interactions, tempo-rhythmic abilities, musical accompaniment.

\section{INTRODUCTION}

Starting from 2018 (the World Cup in Bulgaria), the judges began to evaluate the level of difficulty of the compositions with an open scale according to the rules of the competition. This innovation has become promising for the further development of rhythmic gymnastics as a kind of Olympic program. Ranking of sportswomen based on the level of execution skills became more adequate. Competitive programs with all apparatuses have become more dynamic and interesting. The difficulty of competitive routines has equally increased from 2018 to 2019 . It is connected with the opening of evaluation scale and with including a greater number of motor interactions into group routines. The difficulty of the programs has increased rapidly by 7 points in average. It can be traced in two types of all-around (Table 1). The variation coefficient indicates the degree of teams' uniformity in difficulty. As the routines of leading teams are a kind of standard, so many teams pursue the same indicator of difficulty, which sets higher demands to 
synchronization of gymnasts' motor actions, directly connected with their tempo-rhythmic abilities. Gymnasts began to include a greater variety of different elements with a high coordination difficulty in their compositions, which increased the spectacular effect of their performances (Terekhina et al., 2018).

Today, the importance of information, aesthetic and emotional factors as important components in all spheres of activity, such as mu- sic, painting, architecture, literature and sports, etc. has significantly increased in the world.

The carried out analysis of scientific works devoted to the importance of composition, allowed to reveal a pattern - in all spheres of activity, there are laws of composition, which authors are obliged to follow, but still they all obey the aesthetic aspect: difficulty, emotion and logic.

Table 1. Comparative analysis of the evaluation of composition at the World Cup (2017), the World Championship (2018), the Europe Championship (2019) (points) (n=24)

\begin{tabular}{lccccccc}
\hline & $\begin{array}{c}\text { The World Cup } \\
\text { (2017) }\end{array}$ & $\begin{array}{c}\text { The World } \\
\text { Championship (2018) }\end{array}$ & $\begin{array}{c}\text { The Europe } \\
\text { Championship (2019) }\end{array}$ & $\begin{array}{c}\text { Statistical } \\
\text { conclusion, } \mathbf{P}\end{array}$ \\
\hline $\begin{array}{l}\text { Routine } \\
\text { evaluation }\end{array}$ & $\mathrm{M} \pm \mathrm{m}$ & $\mathrm{V}(\%)$ & $\mathrm{M} \pm \mathrm{m}$ & $\mathrm{V}(\%)$ & $\mathrm{M} \pm \mathrm{m}$ & $\mathrm{V}(\%)$ & $<0.05$ \\
$\begin{array}{l}\text { With the same } \\
\text { apparatuses }\end{array}$ & $18.13 \pm 0.22$ & 3.27 & $20.86 \pm 0.67$ & 8.45 & $24.00 \pm 1.06$ & 11.64 & $<0.05$ \\
$\begin{array}{l}\text { With different } \\
\text { apparatuses }\end{array}$ & $18.04 \pm 0.18$ & 2.68 & $21.18 \pm 0.34$ & 4.28 & $25.45 \pm 0.40$ & 4.13 & $<0.05$ \\
\hline $\begin{array}{l}\text { Statistical } \\
\text { indicators }\end{array}$ & $\begin{array}{l}\text { Note: } \text { M-arithmetic average value; } \text { m-error of average value; } \text { V-variation coefficient; } \\
P-\text { the significance of differences. }\end{array}$
\end{tabular}

Following these conditions, authors create an image and an idea available to the perception of a spectator. Since it is a question of sport, the aesthetic aspect obliges to study execution skills from the point of view of the model of aesthetic attitude of a person to reality.

The aesthetic principle is inherent in all sports as a display of perfection of physical nature of a person. But in such kind of sport as rhythmic gymnastics, along with other complex coordination sports, the measure of aesthetics is already maximal due to a certain direction of the rules. An increase in difficulties of free compositions in technical and aesthetic sports increasingly puts judges-evaluators in a difficult position. A growing number of sportswomen include maximum elements of the highest difficulty in their free program and perform them technically perfectly. In such a situation only, the aesthetic side may serve as the elusive moment, which gives the possibility of qualitative distinctions in the performances of gymnasts.

Of course, the choice of music for competitive routine makes an undeniable contribution to the compositional decision. The compositional structure of musical accompaniment and the musical form play an important role. The analysis of the World Cup in Bulgaria (Sofia) showed that teams use 3 styles of competitive combinations, depending on the difficulty of the rhythmic pattern they use and the style of musical accompaniment. The most difficult style is an etude-imagery. The degree of synchronization of motor actions with such a choice of musical accompaniment is difficult and requires that sportswomen have additional psychophysical abilities. The competitive composition of Italy with 5 hoops fully complies with the classical laws of music. The 
point of the Golden section falls on $2 / 3$ of the routine (2nd place in the finals). Each aesthetic property can be quantified and evaluated, and, consequently, the degree of compositional difficulty as a whole can be evaluated. Reliable differences were revealed in the developed criteria for evaluating the compositional difficulty of group routines at 95\% confidence probability by Wilcoxon, despite the fact that the world's leading teams are not inferior to each other in difficulty and technique.

The main task is to develop such extraordinary and bright competitive compositions that are clearly identified, easy to remember, but are associated with quite capacious associations and be understandable to the viewer. Modern compositions of the leading teams differ in their uniqueness: unusual originality of throws, catches, formations and variety in formations. On average, each routine includes up to 32-40 technical elements, the difficulty of 0.5 to 1.0 points, the tempo of performance is correspondingly very high.

Thus, there are increased demands to gymnasts' skills of synchronization of difficult motor actions, performed separately and together as well, and only highly developed temporhythmic abilities of gymnasts allow performing such a difficult program without any technical deductions for execution.

Many specialists (Medvedeva et al., 2014; Medvedeva et al., 2018; Shevchuk, Turchina, 2015) note that the main distinctive feature of the group routines of rhythmic gymnastics from individual programs is the simultaneous work of all gymnasts. There are high requirements for sportswomen who have to perform a certain set of technically difficult elements for synchronicity of their execution. When performing a competitive combination of group routines of rhythmic gymnastics, sportswomen need to coordinate their movements not only with each other (the same methods of execution, the same amplitude and rhythm of movements, the accuracy of rearrangements and images), but also with changes in musical tempo and rhythm of the corresponding piece of music (Medvedeva et al, 2014; Medvedeva et al., 2018). That is, the principle of synchronicity is to ensure accurate time accordance between separate components: phases, periods, operations, actions, taking into account the tempo-rhythmic structure of the musical accompaniment. In this regard, a sense of tempo and rhythm is a condition of success of group sports activities of gymnasts, indicating the need to take into account the specifics of the display of this factor in the process of improving the synchronicity of motor actions (Medvedeva et al., 2018; Bespalov, Leonov, 2008).

All of the abovesaid has determined the relevance of the problems of this research.

\section{METHODOLOGY}

Ten high-qualified 18-19-year-old gymnasts from two teams of group routines (sports qualifications - Masters of Sport in rhythmic gymnastics) participated in this research. The degree of development of tempo-rhythmic abilities of gymnasts was studied and an expert evaluation of mistakes in synchronicity of group motor activity was made. A compulsory condition of gymnasts' allowance to participation in testing the abilities was normal or above normal keenness of hearing. While analyzing medical cards on the given indicator of hearing sensor system, we did not find any deviations. Considering that the traditional method of evaluation system of tempo-rhythmic abilities is subjective, we developed a control exercise for evaluating these abilities of gymnasts to discover correlations of inner tempo-rhythm of a sportswoman and musical tempo-rhythm of a piece of music.

In order to carry out the evaluation of the degree of development of the ability, phono- 
grams with a record offive variants of rhythmic pattern that are most often used in rhythmic gymnastics were created beforehand with a computer audio editor (Cubase PRO9). Those five variants of rhythmic pattern are: twobeat dotted ("Old French Song"), three-beat simple ("Playing Hobby-horses"), three-beat dotted ("German Song"), the eighth- two sixteenth ("Neapolitan Song"), syncope ("Krakowiak"). All melodies were chosen from the Children's Album by P. I. Tchaikovsky. The phonograms were records of drum in form of a graphic image of sound wave amplitude overlaid on a metric net (scale of bars) and while playing they were accompanied by the metronome beats with the given tempo figures. Each phonogram consisted of four bars. Sportswomen were supposed to listen to the phonogram and play it twice: along with the playing phonogram with the metronome accompaniment and following an inner count- ing of a gymnast (without musical accompaniment). The record and the playing of a rhythmic pattern by a gymnast were done through the sequential pressing of the midi key on a keyboard connected to the computer and sending a signal to the audio editor $(\mathrm{Cu}-$ base PRO9). The comparison of the rhythm of the original phonogram with its playing by a gymnast was accomplished by means of comparison of graphic images with the calculation of average value of rhythmic deviations according to a metric scale. Thus, an individual level of tempo-rhythmic abilities of a gymnast was evaluated. We calculated the deviation from the given figures according to a number of divisions on the metric scale (the scale of bars) between the graphic image of beats in the original rhythmic pattern and its interpretation by a gymnast. Each division is a notional unit in $1 / 32$ of a bar (Figure 1 ) (Korbakova, Stepanova, 2018).

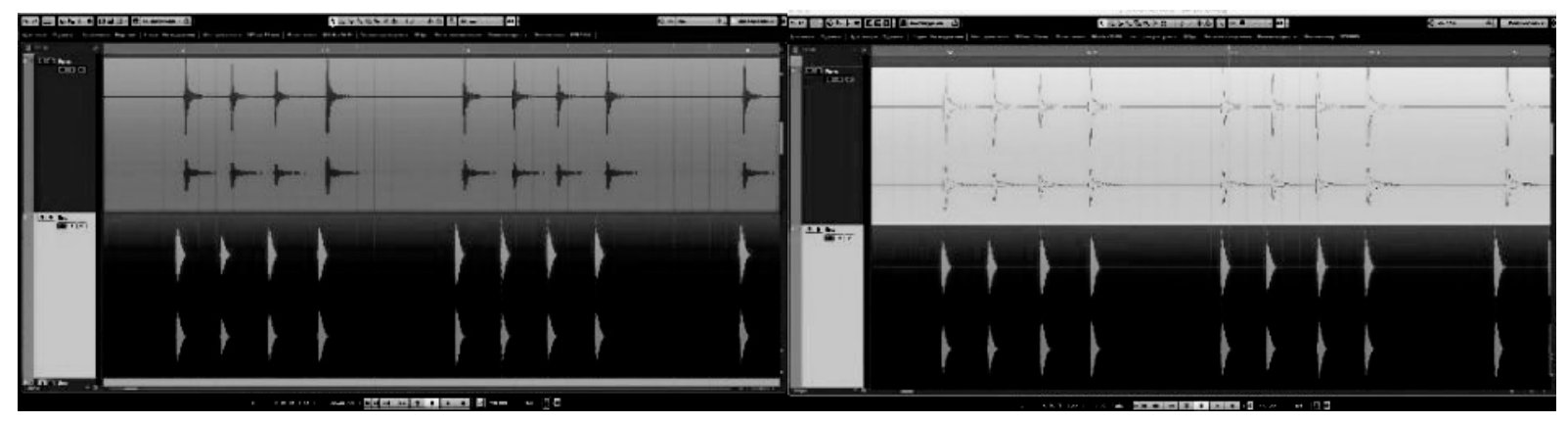

T1

T2

Note: T1 - along with a playing melody; T2 - following an inner counting.

Figure 1. Graphic comparison of metric accents of music and their playing by gymnasts by memory

In Figure 1 there is an example of graphic image of accuracy of playing the melody rhythm by sportswomen. First the melody was played along with the playing melody (T1), and then - following the inner counting (T2). One division was taken as a notional unit. The upper line is the model rhythm and the lower line is the replaying of the rhythm by sportswoman.
The module of the number of deviations from the given in the upper line was calculated.

An expert evaluation of synchronicity of execution of motor actions by sportswomen in group gymnastic routines was carried out according to the types of mistakes in synchronicity of group motor activity identified by N. A. Shevchuk and E. V. Turchina. 
1. Mistakes that break the form of the routine: deviations in axial positions of the body, arms and legs; a shift of the body from a given plane of motion; unintended movement in initial and middle positions; underrotating or over rotating of pivots.

2. Mistakes connected with the level of technical skill of sportswomen: insufficient amplitude in initial, middle and final body positions; angle deviation from an axis of a given pivot or of an axis of a balance; an absence of control over the body parts and head positions during routine.

3. Mistakes in following the tempo-rhythmic structure of elements: a failure in accuracy of positions and transitions, unity of routines and parts of composition: deviations in speed and time parameters of execution (Shevchuk, Turchina, 2015).

The analysis of 6 video records of two teams from the same competitions was conducted in order to determine mistakes in synchronicity of group motor activity. Each violation in researched indicators gave 1-point deduction. An average value of mistakes made by each gymnast in three competitions was calculated. Ten high-qualified gymnasts at the age of $18 \pm 0.5$ years old, who have the sport title - master of sports, took part in the research (5 people in each team). These are the same gymnasts who participated in the evaluation of temporhythmic abilities. Competitive compositions of both teams were identical and had the same difficulty close to the world level. Considering the fact that all the gymnasts are of the same level of technical training, the factor that influences the degree of synchronization of motor actions of gymnasts is tempo-rhythmic abilities. And such factor as execution technique is neutralized. The expert evaluation was conducted by 4 high-qualified judges (having the category - sport judge of the All-Russian category, the number of judges was determined by the rules of the competition FIG). The average deduction out of 4 evaluations was calculated for each gymnast. The degree of concordance of judges was determined according to the coefficient of concordance (it equals 0.9).

\section{RESULTS}

The results of an expert evaluation of synchronicity of execution of motor actions by athletes in group routines are shown in Table 2.

Table 2. Results of an expert evaluation of synchronicity of execution of motor actions by athletes in group routines $(n=12)$

\begin{tabular}{cc|cc}
\hline & $\begin{array}{c}\text { Types of mistakes } \\
\text { (Expert evaluation, points) }\end{array}$ & \multicolumn{2}{c}{$\begin{array}{c}\text { Statistical } \\
\text { indicators }\end{array}$} \\
\cline { 2 - 3 } & Deviations from axial positions of the body, & $\mathbf{M} \pm \mathbf{m}$ & $\mathbf{V ~ ( \% )}$ \\
\hline $\begin{array}{c}\text { Failures in a } \\
\text { routine form }\end{array}$ & $\begin{array}{c}\text { arms and legs } \\
\text { Anift of the body from a given plane }\end{array}$ & $2.50 \pm 0.39$ & 47.14 \\
& $\begin{array}{c}\text { Unintended movements in initial and middle positions } \\
\text { Underrotating or over rotating of pivots }\end{array}$ & $0.90 \pm 0.19$ & 63.07 \\
& $\begin{array}{c}\text { Insufficient amplitude in initial, middle } \\
\text { and final positions }\end{array}$ & $1.20 \pm 0.21$ & 52.70 \\
\hline $\begin{array}{c}\text { Low level of } \\
\text { technical skill }\end{array}$ & $\begin{array}{c}\text { Conditional deviation from an axis } \\
\text { of a given pivot or a shift of a balance axis } \\
\text { An absence of control over body parts } \\
\text { and head position during a routine }\end{array}$ & $0.40 \pm 0.17$ & 129.10 \\
& $\quad$ & $0.60 \pm 0.17$ & 86.07 \\
\hline
\end{tabular}




\begin{tabular}{cccc}
\hline $\begin{array}{c}\text { A failure in } \\
\text { tempo-rhyth- } \\
\text { mic structure } \\
\text { of elements }\end{array}$ & $\begin{array}{c}\text { A failure in accuracy of positions and transitions, } \\
\text { unity of routines and part of composition }\end{array}$ & $6.50 \pm 0.98$ & 45.44 \\
\hline
\end{tabular}

Note: $M$-arithmetic average value; $m$-error of average value; $V$-variation coefficient.

Musical accompaniment for both teams was of a two-beat simple pattern that allows executing all the movements accurately. Despite that fact, during an expert evaluation the sportswomen made a lot of mistakes both in "unintended movements in initial and middle positions" and in "a failure in accuracy of positions and transitions, unity of routines and parts of composition", that lead one another as a consequence, but are evaluated by different brigades of judges. As a rule, inaccurate apparatus throws, and catches are the reasons of such mistakes. In the second place of mistakes in synchronicity of execution are "deviations in speed and time parameters of execution", that are most often revealed in non-simultaneous execution of structural technical elements or asynchronous execution of pivots during the execution of motor interactions. Highqualified gymnasts usually do not make such mistake as an "absence of control over body parts and head position during a routine".

In the process of determining tempo-rhythmic abilities of sportswomen a difference was revealed between the playing of rhythmic pattern along with the playing melody and the playing of the same rhythmic pattern following an inner counting. The difference was 4 points on average and the results were statistically reliable according to Wilcoxon W-criterion where $p<0,05$. It was also determined that the playing of the rhythmic pattern with the faster tempo was done more accurately than with slower tempo but if the rhythmic pattern was simple. The rhythmic pattern such as eighth- two sixteenth and three-beat dotted caused more difficulties when playing with inner counting.

The results of testing of tempo-rhythmic abilities are shown in Table 3.

Table 3. The results of tasting the tempo-rhythmic abilities of gymnasts ( $n=12$, points)

\begin{tabular}{|c|c|c|c|c|c|c|c|c|c|c|}
\hline \multirow{4}{*}{$\begin{array}{c}\text { Testing } \\
\text { of } \\
\text { abilities }\end{array}$} & \multicolumn{10}{|c|}{ Rhythmic pattern } \\
\hline & \multicolumn{2}{|c|}{ Krakowiak } & \multicolumn{2}{|c|}{$\begin{array}{c}\text { Playing } \\
\text { Hobby-horses }\end{array}$} & \multicolumn{2}{|c|}{ Neapolitan Song } & \multicolumn{2}{|c|}{ German Song } & \multicolumn{2}{|c|}{ Old French } \\
\hline & \multicolumn{2}{|c|}{ Syncope } & \multicolumn{2}{|c|}{$\begin{array}{l}\text { Three-beat } \\
\text { simple }\end{array}$} & \multicolumn{2}{|c|}{$\begin{array}{c}\text { Eighth-two } \\
\text { sixteenth }\end{array}$} & \multicolumn{2}{|c|}{$\begin{array}{c}\text { Three-beat } \\
\text { dotted }\end{array}$} & \multicolumn{2}{|c|}{$\begin{array}{c}\text { Two-beat } \\
\text { dotted }\end{array}$} \\
\hline & T1 & T2 & T1 & T2 & T1 & T2 & T1 & $\mathbf{T 2}$ & T1 & $\mathbf{T 2}$ \\
\hline $\mathrm{M} \pm \mathrm{m}$ & $7.0 \pm 0.5$ & $8.8 \pm 1.6$ & $5.0 \pm 1.6$ & $7.2 \pm 1.5$ & $5.2 \pm 1.4$ & $10.5 \pm 4.7$ & $7.9 \pm 1.2$ & $11.7 \pm 2.0$ & $8.0 \pm 1.3$ & $8.6 \pm 1.8$ \\
\hline $\mathrm{V}(\%)$ & 20.2 & 52.7 & 92.9 & 62.7 & 77.9 & 17.5 & 43.6 & 51.1 & 48.9 & 64.1 \\
\hline $\mathrm{P}$ & $\mathrm{p}>0.05$ & \multicolumn{3}{|c|}{$\mathrm{p}<0.05$} & \multicolumn{2}{|c|}{$\mathrm{p}<0.05$} & \multicolumn{2}{|c|}{$\mathrm{p}<0.05$} & \multicolumn{2}{|c|}{$\mathrm{p}>0.05$} \\
\hline
\end{tabular}

Note: notional unit is 1/32 of a bar; T1 - along with the playing melody; T2 - following an inner counting.

$M$-arithmetic average value; $m$-error of average value; $V$-variation coefficient; $P$ - the significance of differences.

A correlation analysis was carried out in order to identify the interrelations between tempo-rhythmic abilities and expert evaluations of synchronicity of motor actions execution by sportswomen in competitive combinations of group routines. The results of correlation analysis are shown in Table 4.

The strongest interrelations were discov- 
ered between an expert evaluation of synchron- abilities during the playing of a three-beat, icity of motor actions execution by sports- two-beat dotted and syncope rhythmic pattern. women in group routines and tempo-rhythmic

Table 4. Correlational interconnections between tempo-rhythmic abilities and expert evaluations of synchronicity of group motor activity $(n=12)$

\begin{tabular}{|c|c|c|c|c|c|c|c|c|c|c|c|}
\hline \multirow{7}{*}{\multicolumn{2}{|c|}{$\begin{array}{c}\text { Expert } \\
\text { evaluation } \\
\text { (mistakes } \\
\text { in synchronous } \\
\text { execution, points) }\end{array}$}} & \multicolumn{10}{|c|}{ Tempo } \\
\hline & & \multicolumn{2}{|c|}{$\begin{array}{c}\text { Very vividly } \\
\text { Allegro } \\
\text { Vivo } \\
\end{array}$} & \multicolumn{2}{|c|}{$\begin{array}{l}\text { Very fast } \\
\text { (Presto) }\end{array}$} & \multicolumn{2}{|c|}{$\begin{array}{c}\text { Quietly } \\
\text { (Andante) }\end{array}$} & \multicolumn{2}{|c|}{$\begin{array}{l}\text { Very moder- } \\
\text { ate (Molto } \\
\text { voderato) }\end{array}$} & \multicolumn{2}{|c|}{$\begin{array}{l}\text { Quite moder- } \\
\text { ate (Molto } \\
\text { voderato) }\end{array}$} \\
\hline & & \multicolumn{10}{|c|}{ Musical time signature } \\
\hline & & \multicolumn{2}{|c|}{$2 \mid 4$} & \multicolumn{2}{|c|}{$3 / 8$} & \multicolumn{2}{|c|}{$2 / 4$} & \multicolumn{2}{|c|}{$3 \mid 4$} & \multicolumn{2}{|c|}{$2 \mid 4$} \\
\hline & & & & & & hythmi & ic patte & & & & \\
\hline & & \multicolumn{2}{|c|}{ Syncope } & \multicolumn{2}{|c|}{$\begin{array}{c}\text { Three-beat } \\
\text { simple }\end{array}$} & \multicolumn{2}{|c|}{$\begin{array}{c}\text { Eighth-two } \\
\text { sixteenth }\end{array}$} & \multicolumn{2}{|c|}{$\begin{array}{c}\text { Three-beat } \\
\text { dotted }\end{array}$} & \multicolumn{2}{|c|}{$\begin{array}{c}\text { Two-beat } \\
\text { dotted }\end{array}$} \\
\hline & & T1 & T2 & T1 & T2 & T1 & T2 & T1 & T2 & T1 & T2 \\
\hline \multirow{4}{*}{ 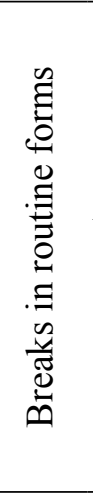 } & $\begin{array}{l}\text { Deviations from } \\
\text { axial positions of } \\
\text { a body, hands }\end{array}$ & 0.388 & 0.042 & 0.118 & 0.233 & 0.0 & -0.021 & 0.064 & -0.203 & 0.382 & 0.397 \\
\hline & $\begin{array}{l}\text { A body shift from } \\
\text { the given plane }\end{array}$ & -0.145 & -0.185 & 0.188 & 0.239 & -0.155 & -0.039 & -0.067 & -0.188 & -0.309 & -0.309 \\
\hline & $\begin{array}{l}\text { Unintended move- } \\
\text { ments in initial } \\
\text { and middle posi- } \\
\text { tions }\end{array}$ & -0.115 & -0.427 & -0.121 & -0.403 & -0.212 & -0.13 & -0.533 & -0.203 & -0.273 & -0.448 \\
\hline & $\begin{array}{l}\text { Underrotating's } \\
\text { or overstating's of } \\
\text { pivots }\end{array}$ & -0.394 & -0.421 & -0.179 & -0.124 & -0.364 & -0.276 & -0.191 & -0.176 & $\mathbf{- 0 . 5 4 5}$ & -0.458 \\
\hline \multirow{2}{*}{ 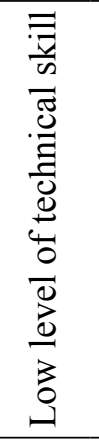 } & $\begin{array}{c}\text { Insufficient } \\
\text { amplitude in } \\
\text { initial, middle and } \\
\text { final } \\
\text { positions }\end{array}$ & 0.052 & 0.324 & 0.424 & 0.209 & -0.339 & -0.091 & 0.579 & 0.545 & -0.061 & 0.118 \\
\hline & $\begin{array}{l}\text { Conditional } \\
\text { deviation from } \\
\text { and axis of } \\
\text { a given pivot } \\
\text { or a shift of } \\
\text { a balance axis }\end{array}$ & 0.052 & -0.070 & 0.03 & 0.209 & -0.218 & 0.152 & 0.064 & 0.0 & 0.303 & 0.391 \\
\hline \multirow{2}{*}{ 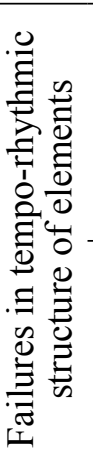 } & $\begin{array}{l}\text { Failure in accu- } \\
\text { racy of positions } \\
\text { and transitions, } \\
\text { unity of routines } \\
\text { and parts of com- } \\
\text { position }\end{array}$ & -0.179 & -0.485 & -0.255 & -0.524 & -0.309 & 0.109 & -0.294 & -0.094 & -0.273 & -0.348 \\
\hline & $\begin{array}{l}\text { Deviations in } \\
\text { speed and time } \\
\text { parameters } \\
\text { of execution }\end{array}$ & -0.233 & 0.073 & 0.167 & 0.115 & 0.242 & 0.0 & 0.497 & -0.303 & -0.312 & -0.297 \\
\hline
\end{tabular}

Critical $r=0,450, p=0,05 ; T 1$ - along with the playing melody; T2 - following an inner counting.

\section{CONCLUSION}

Important characteristics of sportswomen's sense of tempo and rhythm are in accordance with their inner counting and the rhythmic pattern of a chosen musical accompaniment. Gymnasts usually execute absolutely differ- 
ent actions with the same rhythm while they execute motor interactions ("Collaborations" according to "FIG" code).

It is the easiest for gymnasts to adjust to simple two-beat rhythm even if there are deviations in the execution technique. At the same time, the choice of a difficult piece of music by teams assumes a high technical level of sportswomen that allows fulfilling interesting complex coordination compositional decisions of competitive routines, which makes them incomparable and memorable. In this case gymnasts are able not only to express the melody through body but to form a melodic line with apparatuses while executing sequential elements with them.

Thus, it was established that gymnasts' tempo-rhythmic abilities characterize the quality of their synchronized actions and more specifically - the ability of gymnasts to deliver the tempo-rhythmic structure of motor actions to the music.

The data of the correlational analysis revealed that a difficult rhythmic pattern of a chosen musical accompaniment places high demands on synchronization of motor actions of team members that is dependent on sportswomen's high technical level of training. And vice versa, a simple rhythmic pattern (e.g. twobeat) of a chosen musical accompaniment creates optimal conditions for synchronization of actions of all team members. It is influenced by sportswomen's level of technical training and tempo-rhythmic abilities.

\section{REFERENCES}

Bespalov, B.I. and Leonov, S.V. (2008). Diagnostics of sense of tempo and simultaneity of movements of sportswomen in synchronous swimming, Uchenye zapiski universiteta imeni P.F. Lesgafta, Vol. 42 №8, pp. 12-17.

Korbakova,A.A. and Stepanova, I.A. (2018). Musical-rhythmic abilities as a factor that influences the accuracy of formations and synchronicity of execution in discipline "formation" in dancing sport, Uchenye zapiski universiteta imeni P.F. Lesgafta, Vol. 160 № 6, pp. 97-101.

Medvedeva, E.N., Davydova, A.Yu., Suprun, A.A. and Dveirina, O.A. (2018). Tempo-rhythmic characteristics of movements as a factor of synchronization of elements in group routines in rhythmic gymnastics, Uchenye zapiski universiteta imeni P.F. Lesgafta, Vol. 164 № 10, pp. 214-219.

Medvedeva, E.N., Kryuchek, E.S., Suprun, A.A., Tchepakova, N.E., Pukhov, A.M. (2014). Factors that predetermine synchronicity of jumps execution in group routines in rhythmic gymnastics, Uchenye zapiski universiteta imeni P.F. Lesgafta, Vol. 111 № 5, pp. 102-106.

Medvedeva, E.N., Terekhina, R.N., Suprun, A.A., Dveirina, O.A., Davydova, T.Yu. and Davydova, A.Yu. (2018). Objective factors of successful execution of throws in group routines in rhythmic gymnastics, Uchenye zapiski universiteta imeni P.F. Lesgafta, Vol. 160 № 6, pp. 117-123.

Shevchuk, N.A. and Turchina, E.V. (2015). Method of evaluation of synchronicity of motor actions execution by sportswomen in group gymnastic routines, Uchenye zapiski universiteta imeni P.F. Lesgafta, Vol. 130 № 12, pp. 290-293.

Terekhina, R.N., Kryuchek, E.S., Medvedeva, E.N., Viner-Usmanova, I.A. and Dveirina, O.A. (2018). Analisys of results of Europe Championship of rhythmic gymnastics - 2018 in Spain (Guadalajara), Uchenye zapiski universiteta imeni P.F. Lesgafta, Vol. 160 №6, pp. 256-261.

\section{Corresponding author:}

Aleksandra Suprun

Lesgaft National University of Physical Education Sport and Health Summer Olympic Sports Department 35, Dekabristov Street Sankt Peterburg, 190121Russian Federation E-mail: aleksandrass@mail.ru 